\title{
Coscinium fenestratum: Callus and Suspension Cell Culture of the Endangered Medicinal Plant Using Vermicompost Extract and Coelomic Fluid as Plant Tissue Culture Media
}

\author{
Suman Kashyap', Neera Kapoor ${ }^{2}$, Radha D. Kale ${ }^{3}$ \\ ${ }^{1}$ Department of Biotechnology and Centre for Scientific Research and Advanced Learning, \\ Mount Carmel College, Bengaluru, India \\ ${ }^{2}$ School of Sciences, Indira Gandhi National Open University (IGNOU), Maidan Garhi, New Delhi, India \\ ${ }^{3}$ Centre for Scientific Research and Advanced Learning, Mount Carmel College, \\ Bengaluru, India \\ Email: sumkash925@gmail.com
}

Received 29 February 2016; accepted 24 April 2016; published 27 April 2016

Copyright (C) 2016 by authors and Scientific Research Publishing Inc.

This work is licensed under the Creative Commons Attribution International License (CC BY).

http://creativecommons.org/licenses/by/4.0/

(c) (i) Open Access

\begin{abstract}
In vitro tissue culture of hard woody, endangered, medicinal plant Coscinium fenestratum is most challenging to plant tissue culturists. In the present study, petiole and leaf explants of Coscinium fenestratum were induced to form callus when cultured on vermicompost extract media along with coelomic fluid. Suspension medium was developed using vermicompost extract and coelomic fluid in 3:1 ratio. Phytochemical analysis of the alkaloid berberine was confirmed from callus, suspension cell culture and suspension medium by Thin Layer Chromatography and High Performance Liquid Chromatography. Vermicompost and its extracts with coelomic fluid have shown maximum (100 per cent) response of callus induction. Callus mass enlarged with increasing concentration of coelomic fluid and callus growth was assessed from the biomass. Incubation of culture tubes in dark supported callus development significantly. The $R f$ value of 0.36 confirmed the presence of berberine by Thin Layer Chromatography. Qualitative analysis confirmed the presence of alkaloid berberine with the retention time of 2.8 minutes similar to that of standard reference sample from Sigma chemicals, USA. The suspension medium turned deep yellow because of the release of the alkaloid. Vermicompost and its extracts along with coelomic fluid have shown the economical approach for micropropagation of economically and medicinally important plants.
\end{abstract}


Keywords

\author{
Berberine, Coelomic Fluid, Coscinium fenestratum, Plant Tissue Culture Media, Suspension \\ Cell Culture, Vermicompost Extract
}

\title{
1. Introduction
}

Coscinium fenestratum Colebr. (Menispermaceae) is widely spread across the Western Ghats (India) and Sri Lanka. It is commonly known as tree turmeric. The plant has mainly been used for treating diabetes mellitus in the traditional Siddha and Ayurvedic systems of medicine [1]. The stem portions contained many alkaloids like berberine, hentriacontane, ceryl alcohol, sitosterol, oleic acid, palmitic acid and saponin with some resinous material [2]. From roots, tertiary alkaloids, dihydroberlambine, berlambine and noroxyhydrastinine were isolated [3]. Antidiabetic activity of C. fenestratum has been reported [4]. The stem portion is suggested to have anti-inflammatory, thermogenic, antiseptic, tonic effects and used against inflammations, opthalmopathy, ulcers, general debility and jaundice [5]-[7]. Preliminary studies on micropropagation of $C$. fenestratum were reported [8]. Protocol was developed for obtaining berberine-producing callus and cell suspension cultures established from the petiole segments of $C$. fenestratum. With $4 \mathrm{mg} / \mathrm{L}$ of NAA, highest yield of alkaloid berberine was acquired and $2 \mathrm{mg} / \mathrm{L}$ of 2,4-D yielded the best cell growth [9]. Intercellular berberine and berberine recovered from the suspension media were studied [10].

C. fenestratum is listed as endangered in the IUCN Red Data Book and also in the Convention on International Trade in Endangered Species of Wild Fauna and Flora (CITES), because of large scale harvesting of the plant for Pharmaceutical purpose [11]. Therefore, sustainable management of C. fenestratratum is necessary. Significant medicinal properties of this species have made it one of the most exploited species. Naturally C. fenestratum propagates through seeds and vegetative perennial stem cuttings. Earlier research on $C$. fenestratum has confirmed the in vitro callus induction for determination of alkaloid berberine content [12]. Successful in vitro propagation protocols for $C$. fenestratum have not yet been reported. Vegetative propagation of $C$. fenestratum is very slow. Conventional propagation through seeds and vegetative cuttings is not adequate for its conservation and sustainable utilization. Therefore, development of an in vitro protocol for production of planting material is important to conserve this valuable endangered medicinal plant for future generation.

In this present study, an attempt has been made to analyze the response of $C$. fenestratum to vermicompost and its extracts along with coelomic fluid. Suspension cell culture was established and the released alkaloid was analysed.

\section{Materials and Methods}

\subsection{Collection of Medicinal Plant Sample (Explant)}

Stem cuttings and fresh leaves of $C$. fenestratum authenticated in June 2012 by taxonomist, Dr. Rajanna, University of Agricultural Sciences (UAS), GKVK, Bangalore were collected.

\subsection{Preparation of Media}

The MS medium was purchased from the Sigma and final volume $(1 \mathrm{Ltr})$ was made up with distilled water. Fresh vermicompost (30\%) was suspended in sterile distilled water and was subjected to continuous agitation for 8 hours [13]. Five per cent of ethanol and $2.5 \mathrm{mg} / \mathrm{ml}$ of EDTA under cold conditions around $4^{\circ} \mathrm{C}$ were considered for extraction of coelomic fluid from earthworm Eudrilus eugeniae [13]. Coelomic fluid collected was used in 0.1 $10 \mathrm{mg} / \mathrm{L}$ concentration in the vermicompost media. The $\mathrm{pH}$ of the medium was maintained at 6.0 using $1 \mathrm{~N}$ $\mathrm{NaOH} / \mathrm{HCl}$ and $20 \mathrm{ml}$ of the medium was poured into sterile culture bottles. Vermicompost extract and Coelomic fluid were taken in 3:1 ratio for suspension media preparation. Simultaneously, coelomic fluid was used as spray in the in vitro propagation studies during sub culturing of the callus.

\subsection{Callus Induction}

For callus development, petiole and leaf segments of $C$. fenestratum were considered as explants. Callus growth 
was monitored by measuring dry weight of the developed callus.

\subsection{Suspension Culture}

Suspension cultures were initiated by inoculation of one gram of callus into a $125 \mathrm{ml}$ Erlenmeyer flask containing $25 \mathrm{ml}$ of liquid vermicompost and coelomic fluid in 3:1 ratio [14]. The liquid medium was filtered and separated cells were further used for sub culturing and extraction of alkaloids.

\subsection{Preparation of Alcoholic Stem Extract and Phytochemical Analysis}

Extraction with 80 per cent ethanol has given the highest berberine. Suspension culture cells were separated from the media by filtration and extracted with hot methanol (80\%). Alkaloid was extracted from the suspension medium by adopting the earlier research protocol [15].

\subsubsection{Determination of Total Phenolic Content in the Plant Extract}

Total phenolics in callus and suspension cell cultures of $C$. fenestratum were determined by Folin-Ciocalteu's method using Spectrophotometer [14] [16]. The total phenolic content in the plant extract were expressed as mg of gallic acid equivalent (GAEs) per gram of extract (GA mg/gram). Samples were prepared in triplicate for each analysis and the mean value of absorbance was calculated.

\subsubsection{Determination of Total Flavonoid Content in the Plant Extract}

Total flavonoids in the callus and suspension cells of C. fenestratum were measured by aluminium chloride colorimetric assay using Spectrophotometric method [14] [17]. Quercetin was used as standard flavonoid and is expressed in terms of milligrams of quercetin equivalents (QE) per gram of extract. The samples were prepared in triplicates for each analysis and the mean value of absorbance was calculated.

\subsubsection{Thin Layer Chromatography and High Performance Liquid Chromatography}

TLC analysis was experimented according to the earlier research method [18]. HPLC was carried out using C18 column and the solvent system of acetonitrile:water (60:40). The flow rate was $0.5 \mathrm{ml} /$ minute. $20 \mu \mathrm{l}$ of sample was injected at detection wave length of $265 \mathrm{~nm}$ using isocratic mode. Retention time (Rt) of 5.15 minutes for berberine was followed. Suspension media was also taken for HPLC analysis to confirm the release of berberine into the medium.

\subsubsection{Experimental Data Analysis}

ANOVA and Student's t-test were considered for callus induction in various media experimented. Comparative analysis of total phenolics and total flavonoids present in in vivo plants and in vitro suspension cultures of $\mathrm{C}$. fenestratum were performed using Student " $t$ " test. The "P" values less than 0.05 were considered as indicative of significance.

\section{Results}

\subsection{Callus Induction in Coscinium fenestratum}

In the present study, C. fenestratum has been experimented with different treatments to analyze its response. Among the treatments, vermicompost medium and vermicompost extract medium with coelomic fluid have shown maximum (100 per cent) callus induction (Table 1, Figure 1(b)). Light induced the darkening of the callus tissue. After 4 weeks of callus induction on vermicompost extract medium, callus was transferred to suspension medium containing vemicompost and coelomic fluid in 3:1 ratio. The suspension media turned deep yellow because of the release of alkaloid (Figure 1(c) and Figure 1(d)). Yellow substance was freeze dried and was extracted with 80 per cent ethanol and subjected to Dragendrof's reagent which showed fluorescent colour under UV which confirmed positive test for berberine [19].

\subsection{Phytochemical Analysis}

In vitro suspension cultures have shown significantly higher total phenol content (25.6 $\pm 0.23 \mathrm{mg} / \mathrm{gram})$ and 


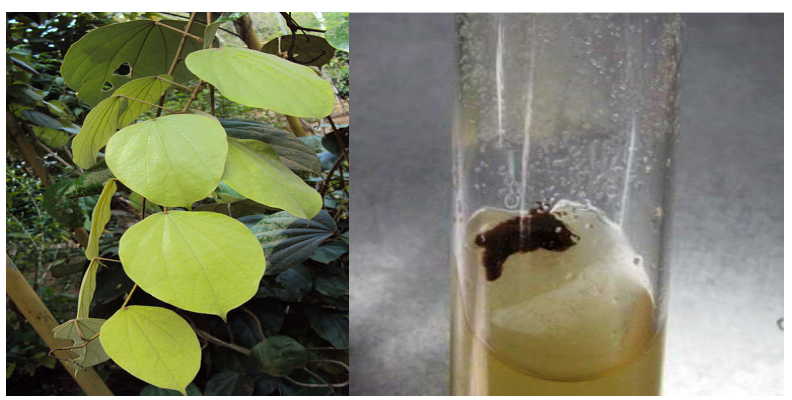

(a)

(b)

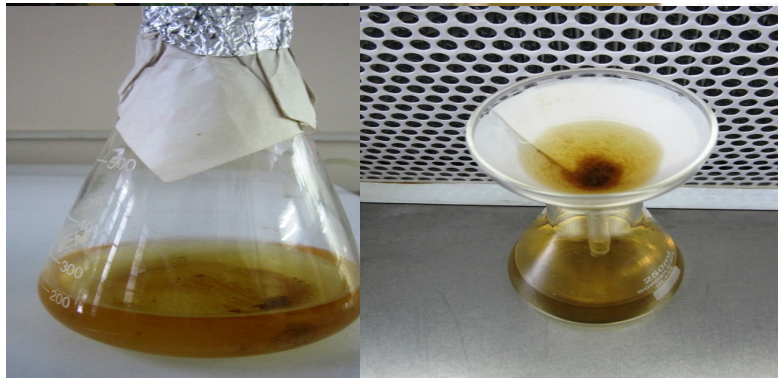

(c)

(d)

Figure 1. (a) Coscinium fenestratum; (b) Callus formation from leaf explant of $C$. fenestratum on vermicompost extract medium; (c) Suspension culture; (d) Separation of suspension cell culture.

Table 1. Effect of media and its chemical supplements on callus induction from leaf explant of Coscinium fenestratum.

\begin{tabular}{|c|c|c|c|c|c|c|}
\hline \multirow{2}{*}{ Media } & \multicolumn{3}{|c|}{$\begin{array}{c}\text { Combination of phytohormones } \\
\text { concentration }(\mathrm{mg} / \mathrm{L})\end{array}$} & \multirow{2}{*}{$\begin{array}{l}\text { Percentage response } \\
\text { of callus induction }\end{array}$} & \multirow{2}{*}{$\begin{array}{l}\text { Number of times } \\
\text { subcultured }\end{array}$} & \multirow{2}{*}{ Observation } \\
\hline & BAP & NAA & IBA & & & \\
\hline MS & 0.5 & 1.0 & 0.1 & 10 & 1 & Callus \\
\hline Vermicompost extract & 0.5 & 1.0 & 0.1 & 60 & 4 & Callus \\
\hline Vermicompost only & - & - & - & 70 & 4 & Callus \\
\hline Vermicompost extract only & - & - & - & 100 & 4 & Callus \\
\hline $\begin{array}{l}\text { Vermicompost + coelomic } \\
\text { fluid (3:1) }\end{array}$ & - & - & - & 98 & 4 & Callus \\
\hline $\begin{array}{l}\text { Vermicompost extract } \\
\text { (explants given } \\
\text { coelomic fluid spray) }\end{array}$ & - & - & - & 100 & 4 & Callus \\
\hline
\end{tabular}

flavonoids content $(0.18 \pm 0.02 \mathrm{mg} / \mathrm{gram})$ on comparison with in vivo plants (Table 2$)$. The undifferentiated cells were at par with the different plant parts in synthesizing the essential compounds of medicinal importance.

The TLC fingerprints of each extract were similar and the major component of cell and callus extracts was alkaloid berberine with the Rf value of 0.55 . Berberine showed yellow fluorescence at UV $366 \mathrm{~nm}$. Similar result was obtained earlier [18].

Qualitative analysis of an alkaloid using HPLC has confirmed the presence of large peak of berberine with the retention time of 5.195 minutes similar to that of standard reference sample from Sigma Chemicals, USA (Figure 2). Suspension medium extracted with 80 per cent ethanol was also considered for qualitative estimation of berberine which showed a peak with retention time of 4.941(Figure 3).

\section{Discussion}

Previous reports have shown that 62 to 97.6 per cent of callus induction from leaf explants and 66.0 to 98.6 per- 


\section{Research Center}

$\begin{array}{ll} & \\ \text { Acquired by } & : \text { Admin } \\ \text { Sample Name } & : C F \\ \text { Sample ID } & : 3 \\ \text { Injection Volume } & : 20 \mu \mathrm{L} \\ \text { Data Filename } & : C F \quad 1 \text { 3,.lcd } \\ \text { Method Filename } & : \text { CF.lcm } \\ \text { Report Filename } & : \text { Default.lcr } \\ \text { Data Acquired } & : 8 / 2 / 20134: 11: 34 \text { PM } \\ \text { Data Processed } & : 8 / 3 / 20131: 10: 43 \text { PM }\end{array}$

Sample Information

Chromatogram

CF E:IHPLCWDatalCF_1_3,licd

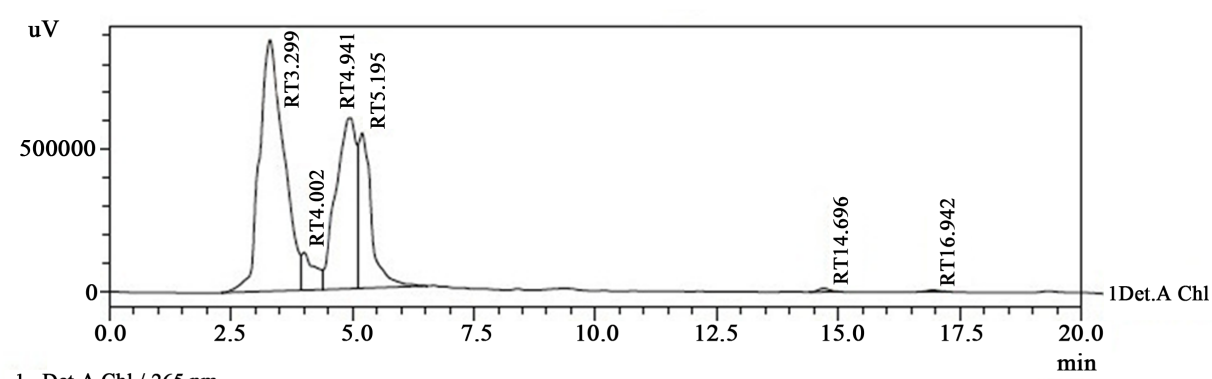

1 Det.A Chl / $265 \mathrm{~nm}$

PeakTable

\begin{tabular}{|c|c|c|c|c|c|}
\hline Name & Peak\# & Ret. Time & Area & Height & Area \% \\
\hline \begin{tabular}{|l|} 
RT3.299 \\
\end{tabular} & 1 & 3.299 & 30768431 & 883261 & 50.353 \\
\hline \begin{tabular}{|l} 
RT4.002 \\
\end{tabular} & 2 & 4.002 & 2482645 & 132144 & 4.063 \\
\hline \begin{tabular}{|l} 
RT4.941 \\
\end{tabular} & 3 & 4.941 & 17084575 & 600615 & 27.959 \\
\hline \begin{tabular}{|l} 
RT5.195 \\
\end{tabular} & 4 & 5.195 & 10482257 & 545624 & 17.155 \\
\hline RT14.696 & 5 & 14.696 & 200086 & 12698 & 0.327 \\
\hline \begin{tabular}{|l|} 
RT16.942 \\
\end{tabular} & 6 & 16.942 & 86870 & 5145 & 0.142 \\
\hline & Total & & 61104864 & 2179488 & 100.000 \\
\hline
\end{tabular}

Figure 2. Chromatogram of berberine extracted from C. fenestratum suspension cell cultures.

\section{Research Center}

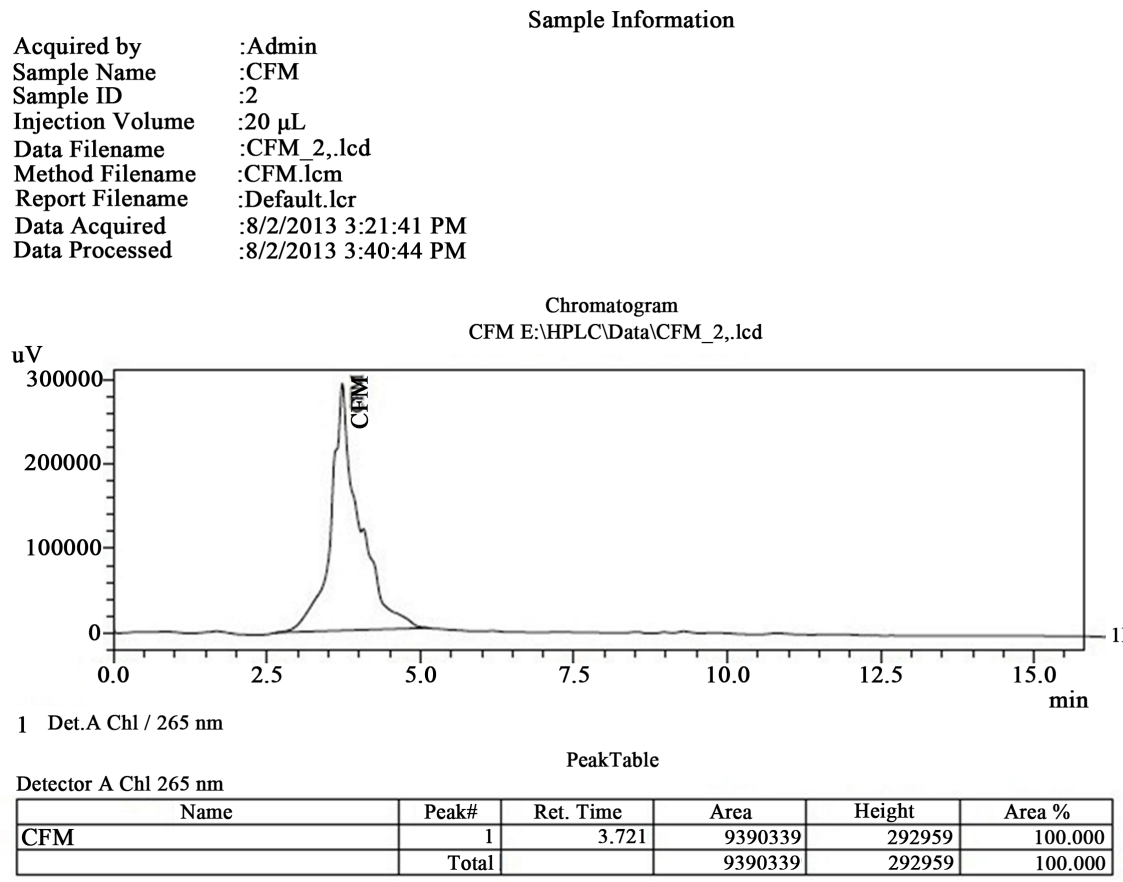

Figure 3. Chromatogram of berberine detected from suspension medium developed for suspension cell culture of $C$. fenestratum. 
Table 2. Comparative analysis of total phenolics and total flavonoids present in in vivo plants and in vitro suspension cultures of $C$. fenestratum and their t-statistical values.

\begin{tabular}{cccc}
\hline Sample & In vitro \pm SE & In vivo \pm SE & t statistical value \\
\hline Phenol Content in $\mathrm{mg} /$ gram & $25.6 \pm 0.23$ & $19.03 \pm 0.08$ & $\mathbf{0 . 0 0 0 0 0 1 *}^{* *}$ \\
Flavonoid content in $\mathrm{mg} /$ gram & $0.18 \pm 0.002$ & $0.108 \pm 0.0008$ & $\mathbf{0 . 0 0 0 0 0 6}^{* *}$ \\
\hline
\end{tabular}

Note: ${ }^{*}$ Significance at 5 per cent level; ${ }^{* *}$ Significance at 1 per cent level.

cent of callus from the petiole. In parallel, biomass with leaf explants ranged from 1380 to $2798 \mathrm{mg}$ and with petiole explants ranged from 1630 to $2825 \mathrm{mg}$ [12].

Generally, 2,4-D seems to be less acceptable in stimulating secondary metabolites in tissue culture system than IAA or NAA [19]. The stem methanolic extract of $C$. fenestratum contained $18.35 \pm 0.56 \mathrm{mg} \mathrm{GAE} / \mathrm{gram}$ of phenolic compounds compared to $9.35 \pm 0.67 \mathrm{mg}$ GAE/gram in leaf extract. The stem of $C$. fenestratum contained highest amount of flavonoid $12.8 \pm 0.88 \mathrm{mg} \mathrm{QE} /$ gram extract and the leaf extract was found to contain $3.2 \pm 0.78 \mathrm{mg}$ QE/gram extract [20].

From the epicotyls explant of $C$. fenestratum, multiple shoots were formed on Murashige and Skoog medium along with $1.0 \mu \mathrm{M}$ kinetin (KIN) and $0.25 \mu \mathrm{M}$ 2,4-Dichlorophenoxy acetic acid (2,4-D) [21]. From explants, maximum of five shoots was obtained in 75-day culture period [22]. Subsequent subcultures enhanced shoot length and number of shoots per explant in the medium containing KIN and 2,4-D. Increased concentrations of cytokinin -butyric acid (BA) or KIN leading to stunting of multiple shoots with slightly small and narrow leaves [22]. Presence of plant growth regulators initially in the medium or administered during the course of in vitro tissue culture seems to have a remarkable effect on the metabolism of secondary metabolites [23]. Production of secondary metabolites in plant cell and tissue culture is because of the action of cell multiplication and division. Growth hormones have a significant role in determining the production potentiality of a tissue culture [24] [25]. Role of auxin-indole acetic acid (IAA) was found to be better than naphthalene acetic acid (NAA) or 2,4-D on secondary metabolite synthesis like in production of thebaine from cell cultures of Papaver bracteatum [26].

Different combinations of preparations from vermicompost and coelomic fluid were adopted for the in vitro studies to identify the best suitable combination for inducing tissue growth. Petiole and leaf culture of $C$. fenestratum provided very good response with respect to the above media and the extent by which the different fractions of vermicompost can bring growth development in various somatic tissues of plants was assessed. Placing the explants in complete dark and maintaining the room temperature helped the development of callus within short period of time.

In vitro tissue culturing of $C$. fenestratum is most challenging to plant tissue culturists, and also shows significant callus development on vermicompost extract media without any chemical supplementation and also on vermicompost medium with coelomic fluid as organic supplement in the media. Of the different fractions of vermicompost studied, $30 \%$ of vermicompost have given the best result. These growth responses were most probably due to hormone-like activity of humic acids from the vermicompost.

Present study has indicated that by standardizing the technique, it is possible to develop plants through in vitro plant tissue culture technique in an economical way. In most cases, innovations have received less attention, in order to increase application of tissue culture technology in producing endangered medicinal plants, it is essential to lower the cost of micropropagule production.

Suspension culture developed for woody medicinal plant provided very good response and the HPLC analysis for the presence of alkaloids showed significant results. Presence of the alkaloid in the suspension medium was confirmed by HPLC analysis. Release of berberine into suspension medium signifies the importance of the alkaloid by the pharmaceutical companies and the efficient protocol for recovery of the alkaloid from the suspension medium without sacrificing the plant.

Tissue culture technology using MS medium is cost-effective for adoption. Cost analysis [14] was carried out to assess the economic implications between MS and vermicompost extract. To prepare one litre MS medium, Rs. 66.58/- is required where as to prepare one litre media using vermicompost and its extracts, Rs. 10.28/- is required which shows the economical approach for micropropagation of economically important plants.

\section{Conflict of Interest}

The authors declare no financial or commercial conflict of interest. 


\section{Acknowledgements}

Thanks are due to Prof. Rajanna, Botanical garden, Gandhi Krishi Vigyan Kendra, Bangalore.

\section{References}

[1] Varier, P.S. (1994) Coscinium fenestratum. In: Indian Medicinal Plants, Compendium of 500 Species, Orient Longman (Ed), Hyderabad, India, 191-193.

[2] CSIR (1950) Coscinium fenestratum. In: The Wealth of India, Publication Information and Directorate, India, 360.

[3] Datta, S.C., Mathur, R.K. and Baruah, J.N. (1998) Minor Alkaloids of Coscinium fenestratum Root. Indian Drugs, 25, 350.

[4] Shirwaikar, A., Rajendran, K. and Punitha, I.S.R. (2005) Antidiabetic Activity of Alcoholic Stem Extract of C. fenestratum in Streptozotocin Nicotinamide Induced Type 2 Diabetic Rats. Journal of Ethnopharmacology, 97, 369-374. http://dx.doi.org/10.1016/j.jep.2004.11.034

[5] Caius, J.F. (1992) The Medicinal and Poisonous Plants of India. Jhodhpur, India, 141-142.

[6] Kiritikar, K.R. and Basu, B.D. (1933) Indian Medicinal Plants. 2nd Edition, Orient Longman, Chennai, 84.

[7] Nadkarani, A.K. (1954) Indian Materia Medica. 3rd Edition, Popular Prakashan, Mumbai, 318.

[8] Nair, L.G. and Seeni, S. (2003) Preliminary Studies on in Vitro Multiplication of Coscinium fenestratum (Gaertn.) Colebr. (Menispermaceae). Journal of Plant Biology, 30, 85-88.

[9] Narasimha, S. and Nair, G.M. (2004) Effect of Auxins on Berberine Synthesis in Cell Suspension Culture of Coscinium fenestratum (Gaertn.) Colebr.-A Critically Endangered Medicinal Liana of Western Ghats. Indian Journal of Experimental Biology, 42, 616-619.

[10] Narasimha, S. and Nair, G.M. (2004) Release of Berberine and Its Crystallization in Liquid Medium of Cell Suspension Cultures of C. fenestratum (Gaertn.) Colebr. Current Science, 86, 1369-1371.

[11] Jayaweera, D.M.A. (1982) Medicinal Plants Used in Sri Lanka. National Science Council, 47/5, Maitland Place, Colombo, 70-71.

[12] Khan, T., Krupadana, D. and Anwar, S.Y. (2008) The Role of Phytohormone on the Production of Berberine in the Calli Cultures of an Endangered Medicinal Plant Coscinium fenestratum. African Journal of Biotechnology, 7, 32443246.

[13] Kashyap, S., Kapoor, N. and Kale, R.D. (2015) Effect of Vermicompost Extracts on the in Vitro Micropropagation of Bacopa monnieri. International Journal of Green Pharmacy, 9, 63-68. http://dx.doi.org/10.4103/0973-8258.150930

[14] Kashyap, S., Kapoor, N. and Kale, R.D. (2015) Callus Induction and Tissue Differentiation of Tinospora cordifolia on Using Vermicompost and Its Extracts along with Coelomic Fluid as Tissue Culture Media. Horizon Journal of Microbiology and BiotechnologyResearch, 1, 001-007.

[15] Nakagawa, K., Konagai, A., Fukui, H. and Tabata, M. (1984) Release and Crystalization of Berberine in the Liquid Medium of Thalictrum minuscell Suspension Cultures. Plant Cell Reports, 3, 254-257. http://dx.doi.org/10.1007/BF00269306

[16] Singleton, V.L., Orthofer, R. and Raventos, L.R.M. (1999) Analysis of Total Phenols and Other Oxidation Substrates and Antioxidant by Means of Folin-Ciocalteu Reagent. Methods in Enzymology, 299, 152-178. http://dx.doi.org/10.1016/S0076-6879(99)99017-1

[17] Quettier-Deleu, C., Gressier, B., Vasseur, J., Dine, T., Brunet, C. and Luyckx, M. (2000) Phenolic Compounds and Antioxidant Activities of Buckwheat (Fagopyrum esculentum Moench) Hulls and Flour. Journal of Ethnopharmacology, 72, 35-42.http://dx.doi.org/10.1016/S0378-8741(00)00196-3

[18] Rojsanga, P., Gritsanapan, W. and Suntornsuk, L. (2006) Determination of Berberine Content in the Stem Extracts of Coscinium fenestratum by TLC Densitometry. Medical Principles and Practice, 15, 373-378. http://dx.doi.org/10.1159/000094272

[19] Nair, A.J., Sudhakaran, P.R., Madhusudana, J.R. and Ramakrishna, S.V. (1992) Berberine Synthesis by Callus and Cell Suspension Cultures of Coscinium fenestratum. Plant Cell, Tissue and Organ Culture, 29, 7-10. http://dx.doi.org/10.1007/BF00036139

[20] Santhosh, W.G. and Asha, A. (2013) Evaluation of Antimicrobial and Antioxidant Activity of Stem and Leaf Extracts of Coscinium fenestratum. Asian Journal of Pharmaceutical and Clinical Research, 6, 218-221.

[21] Murashige, T. and Skoog, F. (1962) A Revised Medium for Rapid Growth and Bioassay with Tobacco Tissue Cultures. Physiology and Plants, 15, 472-497.

[22] Senarath, W.T.P.S.K. (2010) In Vitro Propagation of Coscinium fenestratum (Gaertn.) Colebr. (Menispermaceae) — An 
Endangered Medicinal Plant. The Journal of the National Science Foundation of Sri Lanka, 38, 219-223. http://dx.doi.org/10.4038/jnsfsr.v38i4.2648

[23] Gamborg, G.L., Constabel, F., La Rau, I.A.G., Millar, R.A. and Steck, W. (1971) The Influence of Hormones on Secondary Metabolite Formation in Plant Cell Cultures. Les Cultures de Tissues de Plantes, 30, 335-344.

[24] Kurz, W.E.W. and Constabel, F. (1979) Plant Cell Cultures, a Potential Source of Pharmaceuticals. Advances in Applied Microbiology, 25, 209-240. http://dx.doi.org/10.1016/S0065-2164(08)70151-5

[25] Staba, E.J. (1980) Plant Tissue Culture as a Source of Biochemicals. CRC Press, Boca Raton, Florida.

[26] Furuya, I., Kojima, H. and Syono, K. (1971) Regulation of Nicotine Biosynthesis by Auxins in Tobacco Callus Tissue. Phytochemistry, 10, 529-1532. http://dx.doi.org/10.1016/0031-9422(71)85018-5

\section{Abbreviations and Acronyms}

Abb1: MS-Murashige and Skoog;

Abb2: KIN_kinetin;

Abb3: 2,4-D-2,4-Dichlorophenoxy acetic acid;

Abb4: GAEs-gallic acid equivalent;

Abb5: QE-Quercetin equivalents;

Abb6: BA-butyric acid;

Abb7: NAA — Naphthalene acetic acid;

Abb8: IAA — Indole acetic acid. 